\title{
Medical methods of abortion using lowest effective dose of mifepristone and misoprostol: case study of 100 women
}

\author{
Mehvish Anjum*, Nivedita D.
}

Department of Obstetrics and Gynecology, Khaja Banda Nawaz Institute of Medical Sciences, Kalaburagi, Karnataka, India

Received: 09 May 2017

Accepted: 31 May 2017

*Correspondence:

Dr. Mehvish Anjum,

E-mail: meetmehvish@yahoo.com

Copyright: (c) the author(s), publisher and licensee Medip Academy. This is an open-access article distributed under the terms of the Creative Commons Attribution Non-Commercial License, which permits unrestricted non-commercial use, distribution, and reproduction in any medium, provided the original work is properly cited.

\section{ABSTRACT}

Background: Medical abortion or Medical Methods of abortion (MMA) (or Chemical abortion) is defined as "the non-surgical way of termination of termination of pregnancy by a drug or combination of drugs". With introduction of MMA there has been a steep rise in abortion related complications due to irrational use of these drugs. This study is undertaken using lowest effective dose of mifepristone and misoprostol in 100 women willing for termination of pregnancy with period of gestation <49 days to study the efficacy, side effects and failure rate. Present study emphasizes on using MMA by proper selection of patient, adhering to proper schedule under provision of MTP Act (counselling, consent, examination, confirmation of pregnancy, prescription by a registered medical practioner) in order to enhance efficacy and avoid complications.

Methods: Prospective Clinical Study consist of use of single dose of 200mg of mifepristone orally followed by misoprostol $(400 \mu \mathrm{g})$ by vaginal route for terminating pregnancy in $\leq 49$ days of gestation. Statistical analysis done by Chi square test.

Results: In this study, success rate i.e. complete abortion without requiring surgical procedure was $96 \%$ and failure rate was $4 \%$. Nausea (56\%) is the most common side effect of Mifepristone. Chills (33\%) is the most common side effect of Misoprostol. Mean Induction Abortion Interval is 2.17 \pm 1.2 hrs. Mean Duration of Bleeding is $7.79 \pm 4.42$ days.

Conclusions: Medical abortion is a promising method of early abortion in a developing country like India as it requires no technical skills and manpower with a good safety profile.

Keywords: Abortion, Bleeding, Mifepristone, Misoprostol

\section{INTRODUCTION}

Abortion is an essential part of family size. India's Medical Termination of Pregnancy (MTP) Act was passed by Indian parliament in August 1971 and implemented in April 1972. Earlier, surgical abortion was used, but nowadays MTP can also be done using various drugs. ${ }^{1}$ With introduction of MMA there has been a steep rise in abortion related complications due to irrational use of these drugs. Unsafe abortions far outnumber safe abortions and contribute to almost $8 \%$ of overall MMR. Out of 6.7 million induced abortions that take place every year, 4 million are unsafe leading to the death of almost 213 Women per day. ${ }^{2}$ Many studies have been conducted to observe efficacy of medical abortion as well as route, schedule and dosage of drugs. Present study uses lowest effective dose of 2 drugs i.e. Mifepristone and Misoprostol sequentially for Medical abortion up to 49 
days (7 weeks) of pregnancy. Present study emphasizes on proper selection of patient, adhering to proper schedule under provision of MTP Act (counseling, consent, examination, confirmation of pregnancy, prescription by a registered medical practioner).

\section{Pharmacology of mifepristone and misoprostol}

Mifepristone primarily known as 'Abortion Pill' is an orally active synthetic steroid with potent antiprogestin, anti-glucorticoid and weak antiandrogen action. ${ }^{3}$ Mifepristone antagonizes all actions of progesterone (which is an indispensible support of growing embryo) on prostaglandin (PG) synthesis and catabolism and stimulates its production resulting in abortifacient effect. It makes uterus about five times sensitive as usual to PG analogues. When administered orally, it is easily absorbed reaching peak serum concentration in pregnant and non-pregnant women in minimum $2 \mathrm{hrs}$ regardless of dose. Over First $72 \mathrm{hrs}$, total serum concentration is comparable for woman administered 200 or $600 \mathrm{mg}$ as single oral dose. Similar peak concentration of 2-2.5 $\mathrm{ug} / \mathrm{ml}$ occur in women given $200,400,600$ or $800 \mu \mathrm{g}$ of mifepristone. $50 \mu \mathrm{g}$ produces subtherapeutic levels. Hence, Mifepristone was used in the dose of $200 \mathrm{mg}$ orally which is lowest effective therapeutic dose.

The effect of Mifepristone develops over 24-48 hours and is the basis of regimen for early medical abortion in which orally administered Mifepristone is followed by 36 to 48 hrs later by PG anologue i.e. Misoprostol. This is the rationale for sequential regimen of administration of two drugs. ${ }^{4}$ Misoprostol a synthetic PG analogue, initially approved by FDA to be taken orally for treatment of gastric ulcers has become important in obstetric gynaec practice because of its uterotonic and cervical ripening properties. It is a synthetic PGE1 Analog (15-deoxy-16hydoxy-16-methyl PGE1). It increases collagenase enzyme in cervical tissue leading to ripening (softening) of cervix and its dilatation.

After oral administration, misoprostol is rapidly absorbed and converted into active metabolite, misoprostol acid. Plasma concentration of misoprostol acid peaks in $30 \mathrm{~min}$ and rapidly decline thereafter. By vaginal route, plasma concentration of misoprostol acid peaks in 1-2 hours and then decline slowly. Vaginal route results in slow increase and lower peak plasma concentration than oral administration (hence less side effects) but overall exposure is increased. ${ }^{5}$ Hence, vaginal route was preferred.

Considering the pharmacokinetics and study side effects profile of drugs, present study is undertaken to study the efficacy of single and lowest dose of 200mg of mifepristone followed by misoprostol $(400 \mu \mathrm{g})$ by vaginal route for terminating pregnancy in $\leq 49$ days of gestation. This is in accordance with the recommendations of Drug Controller of India.

\section{METHODS}

A Clinical study and Medical abortion is undertaken in a Tertiary care centre after obtaining permission from Institutional ethical committee. Study population is women willing for termination of pregnancy with period of gestation $\leq 49$ days calculated from $1^{\text {st }}$ day of last menstrual in a 28-day cycle confirmed by TVS (Transvaginal ultrasound).

\section{Study design}

Prospective clinical study.

\section{Study population}

Women willing for termination of pregnancy with amenorrhea $\leq 49$ days presenting to department of OBGY, in a Tertiary care Centre approved for MTP over 3 months. Sample size was 100.

\section{Inclusion criteria}

- Women willing for termination of pregnancy with amenorrhea $\leq 49$ days

- Patient should accept the project time-frame for medical abortion(14days)

- Should be willing to return for minimum 3 recommended clinical visits

- Easy physical or telephonic access to back-up or emergency facilities

- Consent for surgical procedure in case of failure or excessive bleeding.

\section{Exclusion criteria}

- Undiagnosed adenexal mass, Confirmed or suspected ectopic pregency

- $\quad$ IUCD in situ

- $\quad$ Pregnancy with fibroid

- $\mathrm{Hb}<8 \mathrm{~g} \%$

- $\quad$ History of smoking (age $>35$ years)

- Cardiovascular problems [ angina, valvular disease, arrhythmia, uncontrolled hypertension (BP $>160 / 100)]$

- Bronchial asthma

- If on anti-tubercular drugs

- Adrenal failure

- Current long term systemic corticosteroid therapy

- Inherited porphyrias

- Uncontrolled seizure disorder

- Allergic to prostaglandins

- Acute inflammatory bowel disease

- Glaucoma

- Lack of access to 24 hours emergency services

- Women unable to take responsibility, Anxious women wanting quick abortion, Language or comprehension barrier

- Not willing for surgical abortion in case of failure. 


\section{Day 1/visit 1}

If the chosen method by the women client is medical abortion, then she is given basic information on the medical abortion. Procedure of medical abortion explained and counseling regarding procedure and its side effects done. Sensitive counselling in medical abortion has a larger role because patient is more active participant in abortion process. Detailed counseling decreases the side effects and increases the overall satisfaction rate. ${ }^{6}$ Written informed valid consent is taken in patient's language. It includes consent for medical abortion, consent for resorting to surgical method if medical abortion is failed. Complete general physical and per speculum, per vaginum examination done. Investigations like blood group, $\mathrm{Hb} \%, \mathrm{BT} \mathrm{CT}$ done. Gestational age confirmed by TVS (transvaginal examination). Ultrasonic criteria were used to confirm gestation age in present study. Transvaginal ultrasound is used (because it detects pregnancy about 1 week earlier than abdominal probe ultrasound). Ultrasound findings are documented for medical record. ${ }^{7}$ Only women with a visible gestational sac were eligible. Tab Mifepristone $200 \mathrm{mg}$ given orally on OPD basis in front of the doctor. She is advised to record any side effects and report after $48 \mathrm{hrs}$ i.e. on day 3. She is instructed to report to hospital any time if she experiences acute pain or severe bleeding.

\section{Day 3}

History of bleeding, pain and side effects are recorded. Bleeding could be only spotting, Normal bleeding: Bleeding equal to menses, Heavy bleeding: bleeding more than menses, Severe bleeding: Soaking 2 or more pads per hour for 2 hours continuously with the expulsion of POC. ${ }^{8}$ Tab. Misoprostol $400 \mathrm{mcg}$ is kept vaginally in the posterior fornix and she is counselled that pain and bleeding will start within 1 to 2 hours. She is kept under observation for 4 hours in the hospital. Pulse, Blood pressure and any side effects during the stay is monitored. Usually the pain starts within 1-2 hours. Time of expulsion of products of conception is noted. Most of the women abort within $4 \mathrm{hrs}$ after Tablet Misoprostol administration. Bimanual examination just before discharging her from the facility is performed so that if cervical canal is open and she is about to expel the POC, they can be removed there itself. If cervical canal is closed, she is counselled that she has not aborted and will abort in coming days and discharge her with follow up instruction that she should maintain a menstrual diary in which she should note the amount of bleeding and any symptoms she experience during this period. She should return for follow up on day 14 if everything goes well or otherwise whenever the need arises i.e. in case of severe bleeding.

\section{Day 14}

History of side effects and duration and amount of bleeding noted. TVS done to confirm expulsion. Success is defined as, absence of gestational sac on Day 14 on TVS and no requirement for further medical or surgical intervention beyond the initial dose of vaginal misoprostol.

\section{Failure}

Medical abortion is said to be a failure when clinician has to resort to surgical method of abortion. It could be due to: Severe bleeding/ Haemorrhage, True drug failure or Incomplete abortion. In any case of failure, we have resorted to surgical management i.e. Vaccum Aspiration.

\section{True drug failure}

True drug failure is presence of gestational cardiac activity 2 weeks after mifepristone and misoprostol administration.

\section{Induction Abortion Interval}

Time interval from administration of Misoprostol to passage of products of conception. ${ }^{9}$ Sometimes gestation sac is expelled but patients keep bleeding due to blood clots/ decidual bits in the uterine cavity. This can be managed conservatively up to 36 days as mostly it is expelled spontaneously. But if bleeding is heavy, VA should to be done. Efficacy: Efficacy is defined as, "termination of pregnancy with complete expulsion of conceptus without need for surgical procedure".

\section{Statistical analysis}

Chi square test was used for statistical analysis.

\section{RESULTS}

Table 1 shows study protocolit is a simple and concise protocol for ease of understanding to patient and better follow up thereby enabling continuous medical supervision and prevention of complications.

Table 1: Study consists of 3 visits (study protocol).

\begin{tabular}{|lll|}
\hline Visit & Day & Procedure \\
\hline 1 & 1 & $\begin{array}{l}\text { Counselling, investigations. } \\
\text { Tablet Mifepristone } 200 \mathrm{mg} \text { orally. }\end{array}$ \\
\hline 2 & 3 & Tablet Misoprostol $400 \mathrm{mg}$ vaginally. \\
\hline 3 & 14 & $\begin{array}{l}\text { Confirm and ensure completion of } \\
\text { procedure by TVS. }\end{array}$ \\
\hline
\end{tabular}

Table 2 shows baseline data of 100 women who underwent medical abortion Medical abortion is more common in age group of 21-30 years. The mean age in present study is $28 \pm 4.7$ years. The maximum age observed in present study is 40 years and minimum was 19 years. In present study, maximum women had a previous FTND i.e. in $53 \%$ and $24 \%$ women had previous abortions (20 had surgical abortion and 4 had MMA). 
Table 2: Baseline characteristics.

\begin{tabular}{|ll|}
\hline Baseline characteristics & $\mathrm{N}=100$ \\
\hline Mean age & $28 \pm 4.7$ years (19-40yrs) \\
\hline Gravidity & 4 \\
\hline Primigravida & 96 \\
\hline Multigravida & $43.3 \pm 0.36$ days \\
\hline Mean gestational age & $\mathrm{N}=96$ (Muligravida=96) \\
\hline Previous obstetric outcome & 53 \\
\hline FTND & 17 \\
\hline LSCS & 2 \\
\hline VBAC & 20 \\
\hline Surgical abortion & 4 \\
\hline MMA & \\
\hline Demographic distribution & 88 \\
\hline Urban & 12 \\
\hline Rural & \\
\hline
\end{tabular}

Next common group was of women with previous LSCS. $17 \%$ women had previous LSCS. Women with previous LSCS is can be given medical abortion but with caution i.e. when medical abortion is being carried out in a hospital set up with due monitoring Mean gestational age in present study was $43.34 \pm 36$ days.

Maximum patients (40\%) had gestational age between 43-49 days. $88 \%$ women belonged to urban area, remaining $12 \%$ were from rural areas. This difference may be because of more awareness about medical abortion in urban areas and also 24-hour access to health care services and also facilities for surgical abortion methods which was a pre-requisite for study hence maximum patients selected were from urban areas.

In present study, $91 \%$ women had Induction Abortion Interval $<4 \mathrm{hrs}, 6 \%$ aborted with mifepristone alone, $3 \%$ aborted after $4 \mathrm{hrs}$ of misoprostol administration.

Table 3: Induction abortion interval.

\begin{tabular}{|c|c|c|c|c|}
\hline $\begin{array}{l}\text { Gestational Age } \\
\text { Time of Abortion }\end{array}$ & $\leq 35 n=25$ & $36-42 n=35$ & $43-49 n=40$ & $\mathrm{n}=\mathbf{1 0 0}$ \\
\hline With mifepristone alone & - & 2 & 4 & $6(6 \%)$ \\
\hline After misoprostol $\leq 4 \mathrm{Hrs}$ & 25 & 32 & 38 & $91(91 \%)$ \\
\hline After misoprostol $>4 \mathrm{Hrs}$ & - & 1 & 2 & $3(3 \%)$ \\
\hline Total & 25 & 35 & 40 & $100(100 \%)$ \\
\hline
\end{tabular}

Table 3 shows Induction Abortion Interval: 6\% women aborted with mifepristone alone which is in with consistence with that observed by Ashok et al, 91\% women aborted within $4 \mathrm{hrs}$ of administration of misoprostol which is in consistence with El Refaey (93\%). ${ }^{9,10}$ During this period of observation only one woman has severe bleeding. She was resorted to surgical method of abortion. 3\% women did not abort within 4 hrs. They were discharged and telephonic follow up was kept. They aborted at varying interval. One women reported to emergency room as severe bleeding after 14 hrs and had to undergone surgical evacuation. Another woman aborted at $8 \mathrm{hr}$ normally without any severe bleeding at home. Third women did not abort and reported as missed abortion (gestational sac with no cardiac activity) on day 14 .

Table 4: Mean induction abortion interval.

\begin{tabular}{|lll|}
$\begin{array}{l}\text { Gestational } \\
\text { age (days) }\end{array}$ & $\begin{array}{l}\text { Mean induction } \\
\text { abortion interval (hrs) }\end{array}$ & $\mathbf{n = 1 0 0}(\%)$ \\
\hline$\leq 35$ & $2.3 \pm 1.08$ & 25 \\
\hline $36-42$ & $2.24+1.24$ & 35 \\
\hline $43-49$ & $2.12 \pm 1.20$ & 40 \\
\hline
\end{tabular}

In present study, the overall Mean Induction Abortion Interval is 2.17 \pm 1.20 . $\mathrm{p}=0.8301$ (not significant).
Difference in mean induction abortion in 3 groups are not significant. Table 4 shows Mean Induction Abortion Interval. In this study women were again sub divided into 3 groups according to gestational age to study induction abortion interval, duration of bleeding and bleeding pattern. The three groups were $\leq 35$ days ( $\leq 5$ weeks), 3642 days (5-6 weeks), 42-49 days (6-7weeks). The overall mean induction abortion interval is $2.17 \pm 1.24 \mathrm{hrs}$. The difference in mean induction abortion interval in 3 groups was not statistically significant $(\mathrm{p}=0.8301)$.

Table 5: Mean duration of bleeding.

\begin{tabular}{|lll|}
$\begin{array}{l}\text { Gestational age } \\
\text { (days) }\end{array}$ & $\begin{array}{l}\text { Mean duration of } \\
\text { bleeding (days) }\end{array}$ & $\mathrm{n}=\mathbf{1 0 0}$ \\
\hline$\leq 35$ & $7.48 \pm 3.76$ & 25 \\
\hline $36-42$ & $7.44 \pm 3.03$ & 35 \\
\hline $43-49$ & $8.48 \pm 3.67$ & 40 \\
\hline
\end{tabular}

In present study, the overall Mean duration of bleeding is $7.79 \pm 4.42$ days. $4 \%$ failure rate (excluded from calculating mean duration of bleeding). Range of bleeding was between 2-31 days. $\mathrm{p}=0.39$ (not significant). Difference in mean duration of bleeding in 3 groups not significant. Table 5 shows Mean Duration of Bleeding. The overall Mean Duration of Bleeding is $7.79 \pm 4.42$ days. The Mean Duration of Bleeding 3 different 
gestational age groups was not statistically significant $(\mathrm{p}=0.39)$ i.e. duration of bleeding is not influenced by gestational age when gestational age is $\leq 49$ days. Table 6 shows Bleeding Pattern in the 3 groups. In present study $53 \%$ women experienced heavy bleeding i.e. bleeding more than menses which is similar to that observed by Crenin $(51.8 \%)$ and Shetty et al $(51.4 \%) .{ }^{11,12} 34 \%$ women had Normal bleeding i.e. Bleeding equal to menses. Crenin et al observed normal bleeding in $36.8 \%$ and Shetty et al observed it in $34 \% .^{11,12}$

Table 6: Bleeding pattern.

\begin{tabular}{|lllll|}
\hline Gestational age & $\mathbf{3 5} \mathrm{n}=\mathbf{2 5}$ & $\mathbf{3 6 - 4 2} \mathrm{n}=\mathbf{3 5}$ & $\mathbf{4 3 - 4 9} \mathbf{n}=\mathbf{4 0}$ & Total $\mathbf{n}=\mathbf{1 0 0}$ \\
\hline Type of bleeding & 6 & 2 & - & $8(8 \%)$ \\
\hline Spotting & 17 & 10 & 10 & $37(37 \%)$ \\
\hline Normal & 2 & 21 & 30 & $53(53 \%)$ \\
\hline Heavy bleeding & - & 2 & - & $2 * \%$ \\
\hline Severe bleeding & 25 & 35 & 40 & $100(100 \%)$ \\
\hline Total & & & & \\
\hline
\end{tabular}

In present study, 56\% women had heavy bleeding, $37 \%$ had normal bleeding, $8 \%$ had only spotting. $* 2 \%$ women with severe bleeding were taken for surgical termination. $\mathrm{X} 2$ (chi square) $=30.81$ (highly significant). Difference in Bleeding Pattern Of three gestational age groups was significant.

In present study, $2 \%$ women had severe bleeding i.e. soakage of 2 or more pads in $2 \mathrm{hrs}$ consecutively. These $2 \%$ women were taken for Emergency surgical evacuation and check curretage. The amount of bleeding is statistically significant $(p=30.81)$ i.e. amount of bleeding increases as gestational age increases.

Table 7: Side effects of mifepristone and misoprostol.

\begin{tabular}{|lll|}
\hline Side effects & $\begin{array}{l}\text { Mifepristone } \\
\mathrm{n}=100\end{array}$ & $\begin{array}{l}\text { Misoprostol } \\
\mathrm{n}=100\end{array}$ \\
\hline No Side effects & $27(27 \%)$ & $25(25 \%)$ \\
\hline Nausea & $56(56 \%)$ & $10(10 \%)$ \\
\hline Vomiting & $20(20 \%)$ & $6(6 \%)$ \\
\hline Loose Motions & $5(5 \%)$ & $10(10 \%)$ \\
\hline Fatigue & $21(21 \%)$ & $2(2 \%)$ \\
\hline $\begin{array}{l}\text { Pain in Abdomen } \\
\text { (requiring analgesia) }\end{array}$ & $8(8 \%)$ & $16(16 \%)$ \\
\hline Fever & - & $14(14 \%)$ \\
\hline Chills & - & $33(33 \%)$ \\
\hline Dizziness & $3(3 \%)$ & $5(5 \%)$ \\
\hline Others & $5 *(5 \%)$ & $2 *(\%)$ \\
\hline
\end{tabular}

In present study, $56 \%$ women had nausea as a side effect after mifepristone and chills in $33 \%$ women after misoprostol. *others include headache, feeling of uneasiness, metallic taste in mouth, decrease appetite.

Table 7 shows side effects profile of the 2 drugs. In present study, the side effect profile was similar with that of side effects observed by Scaff et al most common side effect was nausea i.e. $56 \%$ after mifepristone. ${ }^{13}$ Second most common side effect observed was vomiting i.e.
$20 \%$. Noteworthy observation in present study was that $27 \%$ women experienced absolutely no side effects after mifepristone.

The most common side effect that was observed after misoprostol was chills in $33 \%$. Pain is inevitable part of abortion process and every patient is ought to have pain. This pain coincided with expulsion of products of conception. Significant pain i.e. pain requiring analgesia was observed only in $8 \%$ after mifepristone and $16 \%$ after misoprostol.

Vomiting was observed in $20 \%$ women after mifepristone. It was self-limiting and none of the women required antiemetic. Fewer women had vomiting after misoprostol $(6 \%)$ because of vaginal route of administration. $14 \%$ patients had fever but it was $<38{ }^{\circ} \mathrm{C}$ and subsided on its own. None of the women in the whole study showed any signs of infection. Loose motions were observed in 5\% and 10\% women after mifepristone and misoprostol respectively. It was self-limiting, none of the women required anti-diaarhoeal treatment. Other less common side effects that were observed were fatigue, dizziness etc. None of the patients had any adverse effects, none of the women required blood transfusion.

Table 8: Ultrasound (TVS) finding on day 14.

\begin{tabular}{ll} 
Ultrasound finding & Present study \\
Midline echo & $95 \%$ \\
\hline Retained products of conception & $1 \%$ \\
\hline $\begin{array}{l}\text { Gestational sac with no cardiac } \\
\text { activity }\end{array}$ & $1 \%$ \\
\hline Endometrial collection & $1 \%$
\end{tabular}

*2 women who had undergone surgical abortion for failure were not called for TVS on Day 14, hence not included in the Table. Table 8 shows ultrasound finding on Day 14; $95 \%$ women showed midline echo. Gestational sac with with no cardiac activity in $1 \%$, 
retained products of conception in $1 \%$; they were managed by surgical abortion.1 women had endometrial collection, she was observed by weekly scans till no collection was present (managed conservatively) and she stopped bleeding on day 21 .

Table 9: Outcome of medical abortion.

\begin{tabular}{|ll|}
\hline Outcome & $n=100$ \\
\hline Success rate & $96 \%$ \\
\hline Failure rate & $4 \%$ \\
\hline
\end{tabular}

Table 9 shows the Outcome of this study. Complete abortion with medications without any surgical intervention was the primary point of present study. In present study, successful clinical outcome i.e. complete abortion was observed in $96 \%$ women which is in consistence with studies conducted by Ashok et al who reported an overall success rate of $98.5 \%$, Scaff et al (97\%), Guest and Chain (96\%), Crenin et al (94\%).

\section{Details of each failed case}

\section{Case 1}

A 32-year-old $\mathrm{G}_{3} \mathrm{P}_{1} \mathrm{~L}_{1} \mathrm{~A}_{2}$ with 37 days of gestation, Blood group $\mathrm{A}+$ and $\mathrm{Hb} 11 \mathrm{~g}$ had taken Tablet mifepristone on day 1. On day 3 she had come for Tablet misoprostol. She started bleeding per vaginum after 2 hours of misoprostol. By the end of $4^{\text {th }}$ hour she had soaked 6 pads. She was a case of severe bleeding hence her Surgical Evacuation and Check Curettage was done.

\section{Case 2}

A 30-year-old $\mathrm{G}_{5} \mathrm{P}_{2} \mathrm{~L}_{2} \mathrm{~A}_{2}$, blood group $\mathrm{B}+\mathrm{ve}, \mathrm{Hb} 10.5$. She received Tab. Mifepristone on day 1 and came for Tab. Misoprostol on day 3. Even after $4 \mathrm{hrs}$ of insertion of Tablet Misoprostol she did not started bleeding. Her vitals were normal and on per vaginum examination os was closed and there was no bleeding. She was discharged with instruction that she is likely to abort in next 24 hrs and she should maintain pad count strictly.

After 14 hrs of discharge she reported to emergency room with complaints of soakage of 5-6 pads in last $1 \mathrm{hr} 30$ min associated with passage of clots. She managed by surgical Evacuation and Check Currettage.

\section{Case 3}

An old 26 year $\mathrm{G}_{3} \mathrm{P}_{2} \mathrm{~L}_{1}$, with blood group $\mathrm{O}+\mathrm{Hb}=11 \mathrm{~g}$. She followed the medical abortion protocol.

She had an abortion induction interval of $1 \mathrm{hr}$. She was having bleeding till day 14 (soakage of 2-3 pads daily). On transvaginal ultrasound, she showed mixed echogenicity shadow of $1.5 \times 1.5 \mathrm{~cm}$ suggestive of retained products of conception. She was managed by manual vaccum aspiration.

\section{Case 4}

A 28 year $\mathrm{G}_{5} \mathrm{P}_{2} \mathrm{~L}_{2} \mathrm{~A}_{2}$, blood group $\mathrm{B}+\mathrm{ve}, \mathrm{Hb}=10.5 \%$ took tablet mifepristone on day 1 and tablet misoprostol on day 3 .

She only had spotting after $1 \mathrm{hr}$ of misoprostol. She did not pass conceptus and while discharge on per vaginum examination her Os was closed and there was no bleeding. On subsequent days, she had spotting. On day 14 she on TVS showed intact gestational sac with no cardiac activity. She was managed by manual vacuum aspiration.

\section{DISCUSSION}

Clinical study of medical abortion using Tablet Mifepristone and Tablet Misoprostol was undertaken in a tertiary care centre (Approved MTP Centre) using lowest effective dose of Mifepristone and Misoprostol. Study was carried out to study success and failure rate of medical abortion using Mifepristone and Misoprostol, their side effects, induction Abortion Interval and duration of bleeding in women of gestational age $\leq 49$ days after written informed valid consent. Out of 100 women opting for medical abortion, 96 had complete abortion. similar success rate has been shown by studies conducted by Crenin et al $(94 \%) .{ }^{11}$

Scaff et al, the advantage of medical abortion is that it has high efficacy at gestational age $\leq 49$ days. ${ }^{13}$ This study emphasizes on proper selection of patients by using various inclusion and exclusion criteria. The advantage of study protocol is that the patient is in constant supervision of the doctor. By studying the bleeding pattern, we have emphasized that in Medical Abortion patient will have bleeding more than menses and it will last for longer duration thus patient should not interpret as incomplete abortion or failed medical abortion till fourteenth day of starting the MMA unless she has severe bleeding. ${ }^{1}$ The benefit of Ultrasonography not only allows us proper dating on first visit but also ensures completeness of medical abortion on third visit (Day 14). ${ }^{7}$ Having a 24 hrs backup for surgical abortion is a must for catering to patients who land up with incomplete abortion. ${ }^{1}$ Studies have shown that medication abortion can be used effectively in developing countries like India, even in rural setup. ${ }^{14}$ With appropriately trained clinicians and well informed clients, medical abortion could provide a safe and effective method of early pregnancy termination that can result in increased access and options for reproductive health care. Thus, medical abortion is a boon to women opting for early termination of pregnancy with minimum complication, privacy and high efficacy.

\section{ACKNOWLEDGMENTS}

Authors would like to thank co-author Dr. Nivedita for her support and patience throughout the study period. 
Funding: No funding sources

Conflict of interest: None declared

Ethical approval: The study was approved by the Institutional Ethics Committee

\section{REFERENCES}

1. Comprehensive abortion care training and service delivery guideline. Ministry of Health and Family Welfare Government of India; 2010.

2. World Health Organization. Unsafe abortion: global and regional estimates of unsafe abortion and associated mortality in 2003. $5^{\text {th }}$ edition. Geneva: World Health Organisation; 2007.

3. Creinin MD, AubÉny E. Medical abortion in early pregnancy. A clinician's guide to medical and surgical abortion. 1999:91-106.

4. Tang OS. Scheer H, Seyberth H, Lee SWH, Ho PC. Pharmacokinetics of different routes of administration of Misoprostol. Human Reproduction. 2002; 17:332-6.

5. Goldberg $\mathrm{AB}$, Greenberg $\mathrm{MB}$ and Danley PD. Misoprostol and pregnancy. N Eng J Med. 2001;344:38-47.

6. Breitbart V. Counselling in Medical Abortion. Am J Obstet Gynecol. 2000;183:26-33.

7. Crenin MD. Use of various ultrasonographic criteria, to evaluate efficacy of mifepristone and misoprostol for medical abortion. Am J Obstet Gynecol. 1999;181:1419-24.

8. Irving M, Bardin CW, Benton L, and Ann Robbins. Early Pregnancy Termination with Mifepristone and
Misoprostol in United States. New Engl J Med. 1998;338(18):1241-6.

9. Ashok W. Penny GC. GMM Flett and Templet on. An effective regimen for early medical abortion: a report of 2000 consecutive cases. Hum Reprod. 1998;13:2962-65.

10. El Refaey H, Templeton A. Early induction of abortion by a combination of oral mifepristone and misoprostol adminintered by the vaginal route. Contraception. 1994;49:111-4.

11. Crenin MD, Courtney A. Mifepristone and Misoprostol Administered Simultaneously versus 24 hrs apart. Obstet Gynecol. 2007;109:885-94.

12. Shetty J. Medical Abortion by mifepristone with oral vs vaginal misoprostol. J Obstet Gynecol India. 2006;56(6):529-31.

13. Scaff EA, Eisinger SH, Stadaluis L, Franks P, Goreand BZ. Suzanne Poppema. Low dose mifepristone $200 \mathrm{mg}$ and vaginal misoprostol for abortion. Contraception. 1999;19:1-6.

14. Winikoff B, Sivin I, Coyaji KJ. The Efficacy of Medical abortion in China,Cuba and India: a comparative trial of mifepristone-mioprostol versus surgical abortion. Am J Obstet Gynecol. 1997; 176:431-7.

Cite this article as: Mehvish A, Nivedita D. Medical methods of abortion using lowest effective dose of mifepristone and misoprostol: case study of 100 women. Int J Reprod Contracept Obstet Gynecol 2017;6:2753-9. 